OPEN ACCESS

Edited by:

Saravanan Thangamani,

Upstate Medical University,

United States

Reviewed by:

Maria Kazimirova,

Slovak Academy of Sciences, Slovakia Carlo José Freire Oliveira, Universidade Federal do Triângulo Mineiro, Brazil

*Correspondence: Shahid Karim

Shahid.Karim@usm.edu

Specialty section:

This article was submitted to

Parasite and Host,

a section of the journal

Frontiers in Cellular

and Infection Microbiology

Received: 13 March 2021

Accepted: 29 June 2021

Published: 20 July 2021

Citation:

Sharma SR and Karim S (2021) Tick Saliva and the Alpha-Gal Syndrome:

Finding a Needle in a Haystack.

Front. Cell. Infect. Microbiol. 11:680264.

doi: $10.3389 /$ fcimb.2021.680264

\section{Tick Saliva and the Alpha-Gal Syndrome: Finding a Needle in a Haystack}

\author{
Surendra Raj Sharma and Shahid Karim * \\ Center for Molecular and Cellular Biology, School of Biological, Environmental, and Earth Sciences, University of Southern \\ Mississippi, Hattiesburg, MS, United States
}

Ticks and tick-borne diseases are significant public health concerns. Bioactive molecules in tick saliva facilitate prolonged blood-feeding and transmission of tick-borne pathogens to the vertebrate host. Alpha-gal syndrome (AGS), a newly reported food allergy, is believed to be induced by saliva proteins decorated with a sugar molecule, the oligosaccharide galactose- $\alpha-1,3$-galactose ( $\alpha$-gal). This syndrome is characterized by an IgE antibody-directed hypersensitivity against $\alpha$-gal. The $\alpha$-gal antigen was discovered in the salivary glands and saliva of various tick species including, the Lone Star tick (Amblyomma americanum). The underlying immune mechanisms linking tick bites with $\alpha$-gal-specific lgE production are poorly understood and are crucial to identify and establish novel treatments for this disease. This article reviews the current understanding of AGS and its involvement with tick species.

Keywords: tick, $\alpha$-gal, alpha-gal syndrome, red meat allergy, hypersensitivity, sugar, microbiome

\section{INTRODUCTION}

Ticks are obligate ectoparasites of vertebrates and depend on hematophagy for nutrition at each stage of their life history. Because of their hematophagous behavior ticks serve as competent vectors of viruses, bacteria, and protozoan pathogens, and are thus important organisms from a global health perspective (Parola and Raoult, 2001). Hematophagy and host specificity of Ixodid ticks contribute to their ability to acquire, maintain, and transmit multiple pathogens and cause tick-biteassociated diseases, such as alpha-gal syndrome (AGS) and tick paralysis (Rochlin and Toledo, 2020). During blood feeding on their host, ticks secrete and introduce a plethora of salivary secretions that modulate the host immune responses and inoculate tick-borne pathogens (Jongejan and Uilenberg, 2004). Several of these pathogens are believed to be responsible for tick-borne infections such as, viral diseases (e.g., Tick-borne encephalitis, Powassan encephalitis, Colorado tick fever, and Omsk hemorrhagic fever), protozoan disease (e.g., babesiosis and theileriosis), and bacterial diseases (e.g., Lyme disease, Rocky Mountain spotted fever, Anaplasmosis, Rickettsiosis, Ehrlichiosis, and Tularemia) (Schwan and Piesman, 2002; Socolovschi et al., 2009; Brites-Neto et al., 2015; Chmelař et al., 2016; Rochlin and Toledo, 2020). In the United States alone, a surveillance study conducted by the Centers for Disease Control and Prevention (CDC) in the period of 20042016 reported that, 77\% of vector-borne disease cases are caused by ticks (Rosenberg et al., 2018). Of the several diseases vectored by ticks, Lyme disease is the most prevalent across the northern hemisphere. The CDC estimates that approximately 476,000 people are diagnosed with the Lyme 
disease each year in the United States (Schwartz et al., 2021). The economic burden caused by tick-borne diseases is increasing each year, and the annual cost of Lyme disease to the United States health care system ranges between $\$ 712$ and $\$ 1.3$ billion, or approximately $\$ 3,000$ per patient (Adrion et al., 2015). In recent years, several tick species are moving and expanding their geographic range. Hence, studies have predicted an increase in tick-borne diseases, including AGS (Commins et al., 2009; Monzón et al., 2016; Raghavan et al., 2019).

Food allergies affect $\sim 32$ million Americans, including 5.6 million children under 18 years of age (Facts and Statistics, 2019). More than 170 types of food can cause allergies, including milk, eggs, peanuts, tree nuts, wheat, soy, red meat, fish, and crustacean shellfish (Commins, 2015; Iweala et al., 2017; Iweala et al., 2018; Yu et al., 2016). Food allergies are responsible for many severe allergic reactions in the United States, and AGS is already common in several regions of the world. In the US alone, the number of confirmed cases of AGS has risen from only 12 in 2009 to 34,000 in 2019 (Wilson and Platts-Mill, 2019; Alphagalinformation.org, 2020; Commins, 2020; Plats-Mill et al., 2020; Binder et al., 2021). Commins (2020) predicted that the percentage of individuals living in endemic tick areas that have been sensitized to $\alpha$-gal ranges from $15-30 \%$. Furthermore, this syndrome is the leading cause of the onset of allergy and anaphylaxis in adults in the United States and is prevalent in the southeastern United States (Pattanaik et al., 2018; Binder et al., 2021; Alpha-Gal Syndrome Subcommittee Report to the TBDWG, 2020). Clinical manifestations of AGS vary among patients, and the onset of AGS may not show clinical signs in sensitized patients. However, $\alpha$-gal sensitization has been reported as a significant risk factor for coronary heart disease, even in people lacking clinical symptoms (Wilson et al., 2019). This review focuses on our current understanding of ticks, including their sialomes, intrinsic factors, and associations with the onset of AGS.

\section{ALPHA-GAL SYNDROME: A PARADIGM- SHIFTING ALLERGY}

Galactose- $\alpha$-1,3-galactose ( $\alpha$-gal) is a disaccharide sugar found in mammalian glycolipids and glycoproteins, except in Old World monkeys, apes, and humans (Galili and Avila, 1999; Galili, 2001; Galili, 2005; Galili, 2013a; Apostolovic et al., 2014; Hilger et al., 2016; Iweala et al., 2017; Iweala et al., 2020). Alphagal has also been reported in bacteria, protozoa, fungi, and red algae (Galili and Avila, 1999; Hodzic et al., 2016; Khoury et al., 2018). In addition, many human pathogens and viruses attach $\alpha$ gal to glycoproteins (Galili and Avila, 1999; Galili, 2013a; Galili, 2020). Generally, non-mammalian vertebrates lack expression of $\alpha$-gal, but with a few exceptions, such as cobra venom, teleost fish eggs, and amphibian skin (Galili and Avila, 1999; Galili, 2001; Gowda et al., 2001). Unlike protein antigens, $\alpha$-gal is a unique antigen that is not denatured by high cooking temperatures, and it is one of the two carbohydrates associated with life-threatening allergic reactions (Apostolovic et al., 2014;
Soh et al., 2015). Hilger et al. (2016) reported that proteins responsible for red meat allergic reactions are glycosylated with $\alpha$-gal. Takahashi et al. (2014) also analyzed $\alpha$-gal antigens in beef and identified new transmembrane proteins, which were aminopeptidase N (AP-N) and angiotensin-converting enzyme 1 (ACE-1). Furthermore, several other heat-stable antigens present in red meat i.e., $\alpha$ and $\beta$ enolase, amino transferase, and creatinine kinase, are also reported to be cross-reacting with red meat allergy patient serum as well as with anti- $\alpha$-gal antibodies (Apostolovic et al., 2014).

AGS, also known as mammalian meat allergy, red meat allergy, or idiopathic allergy, is a unique type of allergy that involves an IgE antibody response to $\alpha$-gal in humans (Commins et al., 2009). Since its discovery in 2007, several efforts have been made to understand this novel form of food allergy (Commins et al., 2011). Typically, food allergies are classified into 1) IgEmediated or 2) cell-mediated (also known as non-IgE-mediated). The IgE-mediated allergic pathway demonstrates the rapid onset of clinical symptoms in less than $30 \mathrm{~min}$ after antigen exposure (Savage et al., 2016; Waserman et al., 2018). As a clinical hallmark, AGS $\alpha$-gal reactions are often severe and sometimes fatal (Fischer et al., 2016). Moreover, depending on the antigen's route, source, and nature, the onset of clinical symptoms of AGS can be immediate or delayed for 2-10 h (Commins et al., 2009; Commins et al., 2016; Steinke et al., 2015). Rapid onset of anaphylactic reactions was reported with cetuximab, a monoclonal antibody, in AGS patients (Chung et al., 2008).

However, as an idiosyncratic clinical feature (Supplementary Figure 2) of AGS, delayed reactions are reported in patients after red meat consumption (Platts-Mills et al., 2015a; Wilson et al., 2017). The mechanism of delayed reaction against red meat in AGS patients is poorly understood; however, it is correlated with several factors involved in meat digestion, absorption, transport, and subsequent presentation to the host immune system (Steinke et al., 2015; Platts-Mills et al., 2015b). An alteration of lipid metabolism is also the main contributor to the delayed response due to the delayed appearance of $\alpha$-gal-associated glycolipids (Steinke et al., 2016; Iweala et al., 2017). Age and atopy are also reported as the cause of AGS development (Gonzalez-Quintela et al., 2014; Villalta et al., 2016; Fischer et al., 2017). In general, AGS occurs in people of all ages with no known genetic predisposition (Commins et al., 2012; Wilson and Platis-Mills, 2019). AGS patients exhibit various clinical symptoms, including urticaria, angioedema, pruritus, and systematic anaphylaxis. Some patients have reported specific symptoms, such as nausea, indigestion, diarrhea, and abdominal discomfort, before AGS onset. However, even after exposure to $\alpha$-gal, other patients reported no appearance of the symptoms listed above, which further highlights the unusual nature of AGS (Platts-Mills et al., 2015b; Wilson et al., 2017). The reported diverse clinical manifestations in AGS patients might be related to the nature of the allergen and dose as well as the presence of other cofactors, such as metabolic variations (Morisset et al., 2012; Wölbbing et al., 2013; Fischer et al., 2016). Variations of lipid or fatty acid metabolism in the host delays the appearance of $\alpha$-gal in the bloodstream and AGS symptom development 
(Steinke et al., 2016). Similarly, the allergen dose and associated host cofactors play a critical role in the progression and severity of AGS (Morisset et al., 2012; Fischer et al., 2016; Wilson et al., 2018; Wilson et al., 2019). An elegant study compared the frequency of delayed anaphylactic reactions against $\alpha$-gal in AGS patients subjected to beef, pork, lamb, and deer meat. Interestingly, the frequency of delayed anaphylactic responses was 53, 47, 9.1, and 7.3\%, respectively (Fischer et al., 2016). One reason for such variation in delayed anaphylactic reactions against red meats in AGS patients might be the presence of variable quantities of the $\alpha$-gal epitope and adjuvant factors, such as lipids (Hendricks et al., 1990; Fischer et al., 2016). The biochemical composition of red meat, its processing, ingestion, and absorption are all equally important in the onset of anaphylactic reactions in AGS patients (Commins et al., 2016). Wölbing et al. (2013) used an oral challenge approach to study the role of cofactors associated with red meat. Including this study, few other studies identified various exogenous and endogenous factors, such as alcohol, physical exercise, nonsteroid analgesic drugs, and menstruation, to be vital in proliferation or increasing severity of the reaction against the red meat (Wölbing et al., 2013; Fischer et al., 2014; Versluis et al., 2016). In addition to red meat, several other food products and medicines containing the $\alpha$-gal antigen, such as gelatin, collagen, and cetuximab, can also cause AGS (Commins et al., 2016; Commins, 2020). Therefore, the use of drugs derived from mammalian products also poses a risk to AGS patients and exacerbates allergic reactions (Commins et al., 2016). Additionally, a high titer of IgE antibodies to $\alpha$-gal in AGS patients adds several complications for cardiovascular disease patients (Wilson et al., 2018). The development of AGS has been a complex mystery. Indeed, some studies have reported an association between tick bites and AGS, the mechanistic details of how a tick bite can lead to the priming of immune cells during hematophagy are still unclear (Commins et al., 2009; Commins et al., 2016; van Nunen, 2018).

\section{A SINGLE SUGAR MAKES ALL THE DIFFERENCE: THE SIGNIFICANCE OF $\alpha$-GAL}

All mammals have an $\alpha$-1,3-galactosyltransferase ( $\alpha 1,3 \mathrm{GT})$ enzyme encoded by the GGTA1 gene; however, during the evolution of Old-World monkeys, apes, and humans, this gene was inactivated due to a frameshift mutation (Galili, 2015). The $\alpha 1,3 \mathrm{GT}$ enzyme is responsible for generating $\alpha$-gal by transferring a galactose residue with an $\alpha-1,3$ linkage to the terminal lactosaminide (Gal- $\beta-1,4-G l c N A c-R)$ on glycolipids and glycoproteins (Galili, 2001; Macher and Galili, 2008). Interestingly, the GGTA1 gene appears to have become nonfunctional during mammalian evolution; while it is still active in marsupials (Lantéri et al., 2002). Since this gene is in the form of a pseudogene in humans, it does not express $\alpha$-gal epitopes. Therefore, humans develop antibodies against $\alpha$-gal, which gives them an advantage in fighting against $\alpha$-gal expressing pathogens (Welsh et al., 1998; Galili, 2013b). Several studies have discussed the benefit of anti- $\alpha$-gal antibody development in humans, including immunogenic stimulation against parasites expressing $\alpha$-gal epitopes, such as Trypanosoma and Leishmania species (Avila et al., 1989). A study conducted in the $\alpha-1,3 \mathrm{GT}$-knockout (GGTA1-Ko or $\alpha 1,3 \mathrm{GT}^{\mathrm{KO}}$ ) mouse model by raising anti- $\alpha$-gal antibodies demonstrated that they induce anti- $\alpha$-gal IgG and IgM antibodies upon inoculation with the human pathogen E. coli O86:B7 (Posekany et al., 2002; Yilmaz et al., 2014). Another study demonstrated a decrease in malarial parasite transmission due to the high titer of anti- $\alpha$-gal IgM antibodies (Yilmaz et al., 2014). These discoveries sparked an interest in $\alpha$-gal pan-vaccines; that is, vaccinating against pathogens or vectors expressing $\alpha$-gal to prevent infections (Soares and Yilmaz, 2016). Two independent studies using this approach successfully reduced Leishmania infections in a $\alpha$ 1,3GT ${ }^{\mathrm{KO}}$ mouse model (Iniguez et al., 2017; Moura et al., 2017). IgG antibodies against $\alpha$-gal are highly abundant and are estimated to be present in the $30-100-\mu \mathrm{g} / \mathrm{ml}$ range in human serum (Galili et al., 1984; Galili et al., 1993). Anti- $\alpha$-gal IgG antibodies persist in newborns at a low level for up to 6 months and gradually increase over 2-4 years until they reach their highest level, which is equivalent to the levels in adults (Galili et al., 1993). The definitive cause, source, and nature of the antigens involved in rising $\alpha$-gal antibody levels at early ages are yet to be determined. Alpha-gal is expressed by various microbes, including Escherichia, Klebsiella, and Salmonella and many of these bacteria belong to human gut microbiome hence production of anti- $\alpha$-gal antibody may be one way to withstand microbial proliferation or confer protection from detrimental effects of pathogen colonization in human body (Galili et al., 1988; Galili, 2013b; Shreiner et al., 2015).

\section{ALPHA-GAL SYNDROME: AN EMERGING WORLDWIDE PHENOMENON}

This emerging tick bite induced food allergy has been reported to occur in seventeen nations worldwide (Table 1 and Supplementary Figure 1). The discovery of AGS worldwide has opened a new avenue for making a connection between AGS patients and tick bites. It has provided insight into how bites from different tick species can induce IgE sensitization in humans. In a few countries, AGS onset was linked to tick bites, however, a direct link between previous tick bites and AGS has not been established (Chinuki et al., 2016). Tick bites were first implicated in AGS in Australia, although $\alpha$-gal was not presented as the cause (Steinke et al., 2015; van Nunen, 2015). Loh and Tang, (2018) reported that Australia is among the countries with the highest AGS and anaphylaxis rates in the world. Similarly, an earlier report estimated that the prevalence of AGS in tick endemic regions is one in every 550 people and is predicted to surge (van Nunen, 2015). In Australia, including the south coast of New South Wales and Sydney coast, AGS cases coinciding with the endemic area inhabited by the Ixodes holocyclus tick have been reported (van Nunen, 2014; Steinke et al., 2015; 
TABLE 1 | List of tick species reported to be associated with alpha-gal syndrome worldwide.

\begin{tabular}{|c|c|c|}
\hline Associated Ticks\# & Country & Reference \\
\hline $\begin{array}{l}\text { Amblyomma americanum } \\
\text { Ixodes holocyclus } \\
\text { Ixodes australiensis }\end{array}$ & $\begin{array}{l}\text { USA } \\
\text { Australia }\end{array}$ & $\begin{array}{l}\text { Crispell et al. (2019); Platts-Mill and Commins, (2013); Khoury et al. (2018) } \\
\text { Hamsten et al. (2013); Apostolovic et al. (2014) }\end{array}$ \\
\hline Ixodes ricinus & $\begin{array}{l}\text { Sweden } \\
\text { Switzerland } \\
\text { Italy } \\
\text { Germany } \\
\text { Norway }\end{array}$ & $\begin{array}{l}\text { Hamsten et al. (2013); Gray et al. (2016); Bircher et al. (2017); Schmidle et al. (2019); van Nunen (2018); Mullins et al. (2012); } \\
\text { Caponetto et al. (2013); Jappe (2014); Calamari et al. (2015); Uasuf et al. (2018); Lied (2017) }\end{array}$ \\
\hline Rhipicephalus bursa & Spain & Mateos-Hernández et al. (2017) \\
\hline $\begin{array}{l}\text { Haemaphysalis } \\
\text { longicornis }\end{array}$ & $\begin{array}{l}\text { Korea } \\
\text { Japan }\end{array}$ & van Nunen (2018); Lee et al. (2013); Sim et al. (2017) \\
\hline $\begin{array}{l}\text { Amblyomma cajennese } \\
\text { species complex.? }\end{array}$ & $\begin{array}{l}\text { Costa Rica } \\
\text { Panama }\end{array}$ & van Nunen (2015); van Nunen (2018) \\
\hline Not identified & Zimbabwe & van Nunen (2015) \\
\hline $\begin{array}{l}\text { Amblyomma } \\
\text { testudinarium }\end{array}$ & Japan & van Nunen (2018); Sekiya et al. (2012); Chinuki et al. (2016); Hashizume et al. (2018) \\
\hline $\begin{array}{l}\text { Amblyomma sculptum } \\
\text { Amblyomma cajennese } \\
\text { species complex.s.s? } \\
\text { Amblyomma variegatum }\end{array}$ & $\begin{array}{l}\text { Brazil } \\
\text { Ivory Coast }\end{array}$ & van Nunen (2018); Kaloga et al. (2016) \\
\hline Amblyomma herbraeum & $\begin{array}{l}\text { South } \\
\text { Africa }\end{array}$ & van Nunen (2015); Gray et al. (2016) \\
\hline Not identified & $\begin{array}{l}\text { France } \\
\text { Turkey } \\
\text { Netherlands }\end{array}$ & $\begin{array}{l}\text { Jacquenet et al. (2009); Morisset et al. (2012); van Nunen (2015); Guillier et al. (2015); Keleş \& Gündüz (2019); Berends and } \\
\text { Elberink (2017) }\end{array}$ \\
\hline
\end{tabular}

\# Association between tick species and AGS is not experimentally established in the listed reports.?: Exact species variant is not specified in reports.

van Nunen, 2015; van Nunen, 2018). There is an interesting story related to discovering the association between tick bite and red meat allergy in the United States. In 2008, in a clinical trial of the monoclonal antibody cetuximab, cancer patients induced IgE antibodies to $\alpha$-gal (Chung et al., 2008). In the same year, an increasing trend in a number of patients with delayed-type red meat allergy were reported in the southeastern United States. A surveillance study conducted by the CDC from 2012-2013 showed significantly higher $\alpha$-gal-directed IgE levels in the southeastern United States, an established A. americanum tick population territory (Tick and Mammalian Meat allergy, 2021). Furthermore, a link between the tick and $\alpha$-gal-related hypersensitivity became more evident when the same surveillance study reported the overlapping of IgE prevalence and the geographical distribution of $A$. americanum. Commins et al. (2011) reported a direct link between tick bites and the development of $\operatorname{IgE}$ antibodies to red meat, which further supported the hypothesis that $A$. americanum tick bites are associated with AGS onset. The incidence of AGS is increasing in the southwest and eastern coastal regions of the United States, which correlates with the expansion and distribution of the Lone Star tick (Commins et al., 2009; Steinke et al., 2015; Raghavan et al., 2019; Commins, 2020). In the United States, the first reports of AGS in 2009 included only 24 officially reported cases, but a recent study put the number at 34,000 confirmed cases (Binder et al., 2021). Wilson et al. (2018) reported an $32 \%$ increase of AGS cases in the southeastern United states, where the Lone Star tick is prevalent. Public repositories show that up to $3 \%$ of the population has AGS (Alpha-gal info, 2020), while misdiagnosed or undiagnosed cases cannot be ruled out (Commins, 2020). The reported AGS cases in Japan suggest that a tick species is responsible for the allergy (Takahashi et al., 2014). Based on the presence of $\alpha$-gal in its salivary glands, the Haemaphysalis longicornis tick has been suggested to be causing AGS (Chinuki et al., 2016). AGS cases in Korea are also believed to be associated with $H$. longicornis tick bites (Chinuki et al., 2016). Similarly, Hamsten et al. (2013) identified traces of $\alpha$-gal in the mid-gut of the Ixodes ricinus tick, which led to the belief that it was involved in causing red meat allergy in Sweden. In this study, researchers compared $\alpha$-gal epitopes from $A$. americanum and $I$. ricinus ticks and reported that they share certain characteristics, although there were specific variations. Additionally, other countries with reported AGS cases include Spain, Germany, Turkey, and Switzerland (van Nunen, 2015). Interestingly, numerous African countries that conducted seroprevalence studies found that individuals have $\operatorname{IgE}$ antibodies specific to $\alpha$-gal. However, there was no indication of any allergic reactions after red meat consumption (Commins and Platts-Mills, 2013a). This observation has led to questions regarding the actual cause of $\alpha$-gal-specific IgE production in those individuals, and it was hypothesized that the cause could include cestodes, ticks, and other ectoparasites (Commins and Platts-Mills, 2013b). A small number of AGS cases in a rural farming community in South Africa suggested a need to conduct more in-depth studies (van Nunen, 2015). The patients with AGS recalled having a tick bite before the onset of AGS symptoms, although the tick species has yet to be determined. Information about AGS cases across Central America is not available. However, Araujo et al. (2016) reported that injected saliva or bites from the tick species belonging to Amblyomma cajennese complex. Amblyomma sculptum induced specific IgE antibodies in an $\alpha-1,3-\mathrm{GT}^{\mathrm{KO}}$ mouse. Similarly, the tick species 
belonging to A cajennese complex, prevalent in Costa Rica and neighboring countries, are thought to be involved in causing AGS (Wickner and Commins, 2014). Several other tick species found in various South and Central American regions belonging to the Amblyomma and Ixodes genera are known for biting humans, although a link to AGS has not yet been established (van Nunen, 2015).

\section{THE ORIGIN OF $\alpha$-GAL IN TICK SALIVA}

In recent years, studies were primarily focused on identification and profiling of $\alpha$-gal antigens in tick saliva and tissues to decipher the connection of a tick bite and AGS.

It is still unclear how tick acquires and presents $\alpha$-gal and primes the host to develop immune response to develop anti- $\alpha$ gal IgE. There are several possibilities these $\alpha$-gal antigens may be residual or recycled mammalian glycoproteins or glycolipids from previous blood meal or may be $\alpha$-gal signatures contributed by tick-acquired viruses, protozoans, or bacteria. However, various evidence suggests that $\alpha$-gal is possibly originating from tick itself. Several studies reported presence of proteins in tick salivary gland, midgut, and saliva cross-reacting with serum from AGS patients and anti $\alpha$-gal antibodies. Presence of $\alpha$-gal was first reported in the midgut of $I$. ricinus (Hamsten et al., 2013). Araujo et al. (2016) also reported presence of $\alpha$-gal antigen in A. sculptum saliva as well further provided evidence that injection of saliva derived $\alpha$-gal antigen or feeding of ticks on $\alpha-1,3 \mathrm{GT}^{\mathrm{KO}}$ mice induce anti $\alpha$-Gal IgE antibodies. Similarly, another study reported $\alpha$-gal epitope-containing tick proteins in Rhipicephalus microplus BME/CTVM23 cells and in Hyalomma marginatum salivary glands (Mateos-Hernández et al., 2017). Furthermore, presence of several proteins from various groups namely vitellogenins, serpin, actin, $\alpha$-macroglobulin, chitinase like lectin and transport or channel-forming proteins with $\alpha$-gal epitope were also identified in protein extracts of $I$. ricinus larvae and adults (Apostolovic et al., 2020). Recently, the presence of $\alpha$ gal-associated antigens in A. americanum and I. scapularis ticks was discovered via multiple approaches, which included, mass spectrometry, immunoblotting, and immunolocalization analysis of tick tissues (Crispell et al., 2019). This study also demonstrated that expression of $\alpha$-gal antigens is highest in partially blood-fed $A$. americanum salivary glands and saliva. Furthermore, this study also provided evidence that these $\alpha$-gal antigens are localized in salivary secretory vesicles (exosomes) of partially engorged A. americanum and I. scapularis ticks (Crispell et al., 2019). Furthermore, detection of $\alpha$-gal in $A$. americanum tick fed on human blood, which lacks $\alpha$-gal, further indicate that alternative recycling mechanism or mechanism producing $\alpha$-gal might exist in ticks. Immunoblot analysis of A. americanum salivary extracts containing $\alpha$-gal antigen following treatment with PNGase F further demonstrated that $\alpha$ gal is bound with protein in N-linked glycosylated form (Crispell et al., 2019). The role of tick $\beta$-1,4-galactosyltransferase ( $\beta$-1,4-GT) in $\alpha$-gal expression was reported in I. scapularis via heterologous gene expression and localization of $\alpha$-gal in $\alpha$-gal-negative cells
(Cabezas-Cruz et al., 2018). However, it is not clear whether proteins glycosylated by $\beta-1,4-\mathrm{GT}$ can also sensitize host to develop anti $\alpha$-gal antibody and also cross-react with protein containing Galactose- $\alpha-1,3$-galactose epitope. Intriguingly, the key enzyme, $\alpha 1,3-G T$, which synthesizes $\alpha$-gal, remains unidentified in tick genomes.

Few studies have reported that tick-borne bacteria such as Anaplasma phagocytophilum and Borrelia burgdorferi sensu lato express $\alpha$-gal and increase $\alpha$-gal signature in ticks, hence, the role of tick microbiome as one possible source of $\alpha$-gal cannot be negated (Cabezas-Cruz et al., 2018; Vechtova et al., 2018; Hodzic et al., 2019). Furthermore, several studies have reported that a few bacteria from Enterboacteriaceae family such as Salmonella; Pseudomonas, Staphylococcus as well as from Rizobiaceae and Caulobacteriaceae family possess enzyme $\alpha 1,3-\mathrm{GT}$ enzyme which can decorate protein with $\alpha$-gal (Hamadeh et al., 1996; Brown et al., 2013; Montassier et al., 2019; Vechtova et al., 2018). Since bacteria from the same family and group are also reported in tick salivary microbiome, it will be intresting to investigate the impact of presence of bacteria in a tick and its relation with $\alpha$-gal signature of tick (Maldonado-Ruiz et al., 2021). Role of tick's microbiome in causing or increasing tick's ability to develop or present $\alpha$-gal antigen is an emerging area of research. In context of the role of tick microbiome in sensitization of humans against $\alpha$-gal during tick feeding, the dual-allergen-exposure hypothesis seems plausible which states that dual exposure of $\alpha$-gal antigen along with addition of tick microbiome in tick-host interaction interface can cause sensitization of host against $\alpha$-gal.

\section{HOST AND TICK FACTORS CONTRIBUTING TO AGS}

Information regarding host factors, which contribute towards development of AGS, is limited; however, there is a significant progress in this area. Studies have reported that despite presence of high titer of anti $\alpha$-gal IgE, some people do not develop AGS (Michel et al., 2014; Villalta et al., 2016). Based on existing evidence few factors (Figure 1), which might contribute to such variation to the host, can be listed as a) host genetic factors such as blood group and atopy b) host microbiome and associated factors such as diet, and medication. Few research studies report variations in anti- $\alpha$-gal response among people with different blood groups. In a study conducted in Sweden, people with blood type $B$ negative were affected by the $\alpha$-gal allergy more often than other blood types (Hamsten et al., 2013). However, this trend contradicts the hypothesis that a protective effect is produced by blood type B (Posthumus et al., 2010). Intriguingly, this relationship seems to be related to the similarities between $\alpha$ gal and blood type B antigen (Gal- $\alpha 1,3$ (Fuc- $\alpha 1,2)-G a l$ ) structures (Posthumus et al., 2010; Bircher et al., 2017). Hamsten et al. (2013) examined the allergy incidence rates, whereas Posthumus et al. (2010) assessed IgE production in affected individuals. These studies further suggest there is a need for more in-depth research to elucidate the AGS onset 


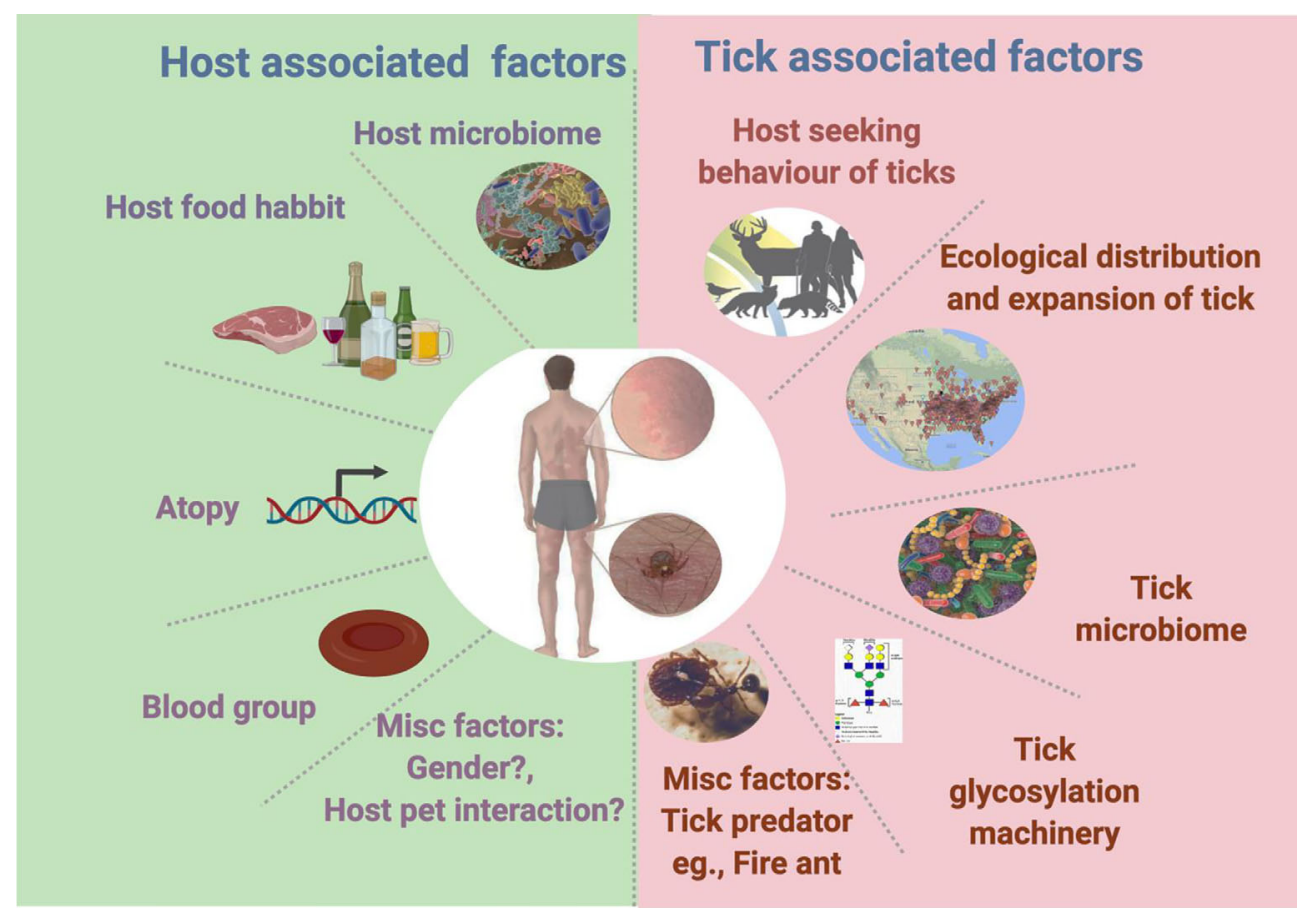

FIGURE 1 | Tick- and host-associated factors linked with alpha-gal syndrome.

mechanisms. However, they introduced the concept of blood type as a factor in acquiring red meat allergy. On the other side, studies have reported genetic predisposition, or atopy, as a critical factor in food allergies (Commins et al., 2009). Individuals with atopy tend to exhibit heightened type I hypersensitivity in immune responses, with excessive $\operatorname{IgE}$ production against common allergens, such as mites, dander, and foods (Justiz et al., 2021). The increase in anti- $\alpha$-gal IgE levels correlates with total IgE levels; thus, atopy was hypothesized to be an associated factor in AGS development (Fischer et al., 2017). One cross-sectional sero-prevalence study described a correlation between anti- $\alpha$-gal IgE levels following tick bites and atopy (Gonzalez-Quintela et al., 2014). In contrast, another study reported that there is no correlation between AGS and atopy (Commins et al., 2012). Since, atopy is linked with multiple genetic factors, age, ethnicity as well as environmental factors hence it is difficult to reject correlation with AGS. A broader study involving wider population considering all possible factors could decipher possible correlation of AGS and atopy.

Various studies have shown that equilibrium of microbiota in epithelial barrier is vital for protection against allergic sensitization and disease development (Iweala and Nagler, 2019; Ohshima, 2013). Studies have demonstrated that shifting of a usual diet towards high fat, low fiber, highly processed food, and indiscriminate use of antibiotics can cause microbiome dysbiosis (Weissis and Hennet, 2017; Wypych and Marsland, 2018). Microbiome dysbiosis is linked to the rising number of cases and prevalence of food allergies in humans (Iweala and
Nagler, 2019; Shreiner et al., 2008). Two central hypotheses could explain such phenomena: the first states that imbalanced microbiota and microbial stimulation can lead to a rise in food allergies. The second states that the imbalance of mucosal-barrier regulation could lead to oral tolerance loss. Current trend shows that incidence of AGS is higher in countries with higher number of allergic cases (Graham-Rowe, 2011; Loh and Tang, 2018; Cabezas-Cruz et al., 2019; Binder et al., 2021). This trend is explained by hygiene hypothesis $(\mathrm{HH})$ which states that exposure of allergen or microbiome in environment at early stage in life reduce risk of development of allergies. Existing literature suggests that $\mathrm{HH}$ is linked with food allergy especially in children with atopy (Iweala and Nagler, 2019). Contrary to that, AGS has been reported mostly in humans with no history of atopy (Wilson and Platts-Mills, 2019; Binder et al., 2021). Interestingly, AGS is reported in people living in rural and urban setting across the globe (Cabezas-Cruz et al., 2019; Binder et al., 2021). Based on existing data it is not possible to reject or accept correlation of AGS with hygiene. There is not enough scientific evidence to accept or reject $\mathrm{HH}$ and more research is needed to decipher a link between AGS and $\mathrm{HH}$.

Discovery of $\alpha$-gal epitope in cat dander prompted researchers to investigate its association with AGS. Though, significant research efforts are made in this area, possible association of cat ownership, $\alpha$-gal sensitization and AGS has not yet been fully rejected or established. There exist two contrasting research reports, one study reports increased level of anti- $\alpha$-gal IgE, however, a study rejected this possibility because anti- $\alpha$-gal IgE positivity was not observed when 
association was investigated by skin prick test (GonzalezQuintela et al., 2014; Bircher et al., 2017).

The jury is out on the question of why only a few tick species can induce AGS. Based on several studies, tick associated factors which can contribute towards AGS can be divided into two categories a) intrinsic factors and b) extrinsic factors. Tick intrinsic factors include the tick microbiome, tick glycosylation machinery, as well as host-seeking and feeding behaviors. On the other hand, tick extrinsic factors may include the geographical distribution of ticks and tick-predator interactions, which limits the tick population. Knowledge of distribution of ticks might be beneficial to evaluate health risk such as AGS, driven by expansion of tick populations. Since distribution of ticks is very wide and driven by multiple ecological factors, inclusion of such factors in ecological models to predict AGS risk assessment, rate of actual exposure and tick bites in certain areas must be considered. Role of tick's intrinsic factors is vital in the context of AGS development. A tick attaches to the host by piercing the skin with its barbed mouthpart (the chelicerate). When anchored into the host skin, it continuously secrets saliva with a plethora of antigens (Francischetti et al., 2009). During blood meal, tick mouthparts induce trauma to the host skin through the breach of skin barrier integrity. This can lead to disruption of the host skin microbiota and facilitate the introduction of tick-borne microbiota (pathobionts) (Bonnet et al., 2017). Tick microbiome can contribute to AGS development possibly via sensitization process during tick bite or by increasing $\alpha$-gal signature in the tick. Key details regarding role of tick microbiome are discussed in earlier section. There is a gap in our knowledge of the tick microbiome and its link to AGS. New cutting-edge tools to manipulate the tick's microbiome are needed to understand the emergence of this unique allergy. A comparative analysis of the microbiome composition residing within different tick species, microbial profiles at tick bite sites may identify the microbial signature involved in AGS development. An urgent question is why, in contrast to other tick species, does one tick species decorates its saliva antigen with the $\alpha$-gal epitope? Presumably, a tick's robust glycosylation machinery is involved in the process of adding $\alpha$-gal to saliva antigens which is responsible for AGS development. Our knowledge of the glycosylation machinery's fitness in different Ixodid tick species is in its early stages. Our earlier work showed that there is a significant difference in the $\mathrm{N}$-glycome profile of $A$. americanum, a tick linked with AGS in comparison to another hard tick, A. maculatum, which is not associated with AGS (Crispell et al., 2019). Furthermore, in the same study, results from the basophil activation test (BAT) demonstrated that tick's ability to elicit $\alpha$-gal sensitization is variable between species (Crispell et al., 2019). Indisputably, glycosylation is a conserved machinery in several taxa of eukaryotes; however, divergence is observed in the subsequent steps, which can generate interspecies- and intraspecies-specific $\mathrm{N}$-glycan profiles (De Pourcq et al., 2010). Ginsberg et al., (2021) found a link between Lyme disease and the tick's host-seeking behavior. The preferred host and latitudinal differences in tick hostseeking behaviors are associated with a specific tick-borne disease's distribution in a particular geography. Since a tick's host-seeking behavior varies among tick species, it can directly affect host encounter and incidence of certain diseases such as AGS. The expansion of the Lone Star tick population from its previously established territories into new geographic ranges has also been suggested as the cause of the increased numbers of AGS cases in new territories (Monzón et al., 2016; Raghavan et al., 2019). This increase in population and expansion into new areas may have been due to a surge in the deer population and the tick's intrinsic ability to succeed in a diverse or changing environment by manipulating the expression of stressmitigating molecules (Monzón et al., 2016; Raghavan et al., 2019; Bullard et al., 2019; Commins, 2020). Wilson et al., (2021) showed a negative correlation between AGS cases and fire ant invasion in the established tick population territories. Since fire ants are known tick predators, it is hypothesized that tick-predator interactions also affect AGS incidence in Lone Star tick endemic areas.

\section{TICK BITE, HOST RESPONSE AND DEVELOPMENT OF AGS}

How a tick bite leads to host sensitization and AGS development is poorly understood. The tick-host interface is a complex battleground. When the tick disrupts the epithelial barrier by causing injury to the host skin by its barbed hypostome, a host driven hemostatic response initiates (Glatz et al., 2017). Hemostatis is the host's innate defense mechanism which is activated against the mechanical injury and includes blood coagulation, platelet aggregation, and vasoconstriction (Francischetti et al., 2009; Kotál et al., 2015). In addition to that, during early stage of the tick's attachment to the skin, humoral and cellular parts of host innate immune system respond with complement activation, inflammation and via infiltration of leukocyte to the bite site (Francischetti et al., 2009). Following the tick bite, activation of keratinocytes, endothelial cells and skin resident leukocytes occurs when they encounter tick saliva or hypostome (Wikel, 2018). Release of antimicrobial peptides, pro-inflammatory chemokines and cytokines including interleukin-8 (IL-8), interleukin-1 $\beta$ (IL$1 \beta$ ), tumor necrosis factor (TNF) by various leukocytes recruits various inflammatory cells including neutrophils (Wikel, 2018). Afterwards, adaptive immune system also branches out in which, activated $\mathrm{T}$ and $\mathrm{B}$ cells (in case of secondary infestation) increases the inflammatory response to tick via release of cytokines and production of antibodies targeted against tick to further activate complement as well as sensitize mast and basophil cells (Kotál et al., 2015; Wikel, 2018). To maintain uninterrupted blood uptake by evading host immune response, tick secretes complex mixture of molecules to reduce pain and itch to the host during feeding. These molecules include saliva vasodilators, inhibitors of platelet aggregation and molecules capable of inhibiting blood coagulation cascades (Francischetti, 2010; Mans, 2011; Kazimirová and Stibrániová, 2013). Furthermore, ticks also release various salivary molecules 


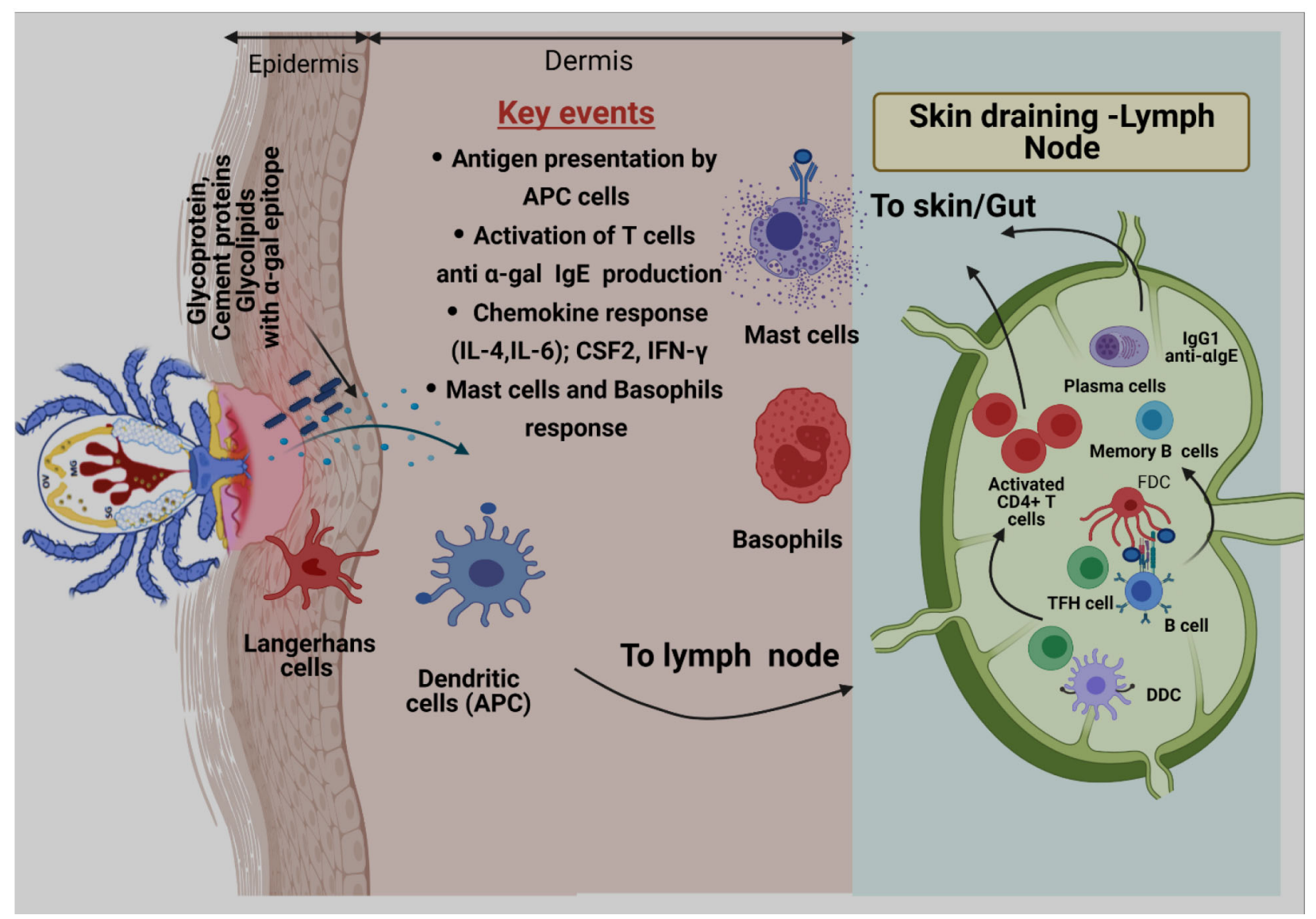

FIGURE 2 | Proposed model of $\alpha$-gal sensitization from tick bites. Skin is comprised of three layers: epidermis, dermis, and hypodermis. Antigen-presenting cells (APCs), including Langerhans cells (LCs) and dermal Dendritic cells (DCs) residing in epidermis and dermis, respectively, respond to tick-secreted antigens, such as glycoproteins, glycolipids, and tick cement-containing $\alpha$-gal moieties. After antigen exposure, APCs process antigen, migrate to skin-draining lymph nodes, and participate in allergen sensitization. During this process, naïve T cells are primed through presentation of tick $\alpha$-gal antigens by LCs and dermal DCs within skindraining lymph nodes. Activated $\mathrm{CD}^{+}{ }^{+} \mathrm{T}$ cells subsequently traffic to the skin through blood and lymphatic vessels. Cognate $\mathrm{T}$ cell help, provided by $\mathrm{T}$ follicular helper (TFH) cells, to $\alpha$-gal-specific B cells leads to germinal center responses, positive clonal selection of B cells via recognition of native antigens retained by follicular dendritic cells (FDCs), and the development of memory B cells and plasma cells. After clonal selection, B cells migrate to the tick bite site on the skin to manifest allergic responses by presenting antigens to T cells, secreting proinflammatory cytokines, and secreting $\alpha$-gal-specific antibodies (anti- $\alpha$-IgE) that ultimately triggers activation of mast cells and basophils and allergic response.

which are involved in lowering production of pro-inflammatory cytokines such as TNF- $\alpha$, interlukin-12 (IL-12) as well as increasing production of anti-inflammatory mediators for example interleukin-10 (IL-10) and transforming growth factor beta (TGF- $\beta$ ) (Ferreira and Silva, 1999; Wikel, 2018). Following tick bite, skewing of T helper 1 (TH1) response towards T helper 2 (TH2) is vital in the process of AGS development. After distruption host skin epithelia by tick bite, in the process of wound healing, M2 macrophages are involved in suppression of inflammation by upregulating anti-inflammatory cytokines like IL-10 or TGF- $\beta$ to alleviate an exaggerated TH1 cell response (Krzyszczyk et al., 2018). In addition, inhibitory action on proinflammatory cytokines (such as IL-1) by salivary molecules further promotes action of M2 polarized macrophages, which leads to inhibition of TH1 immune response and shifts host immune response towards TH2 (Wikel, 2018). Additionally, various other components of tick saliva such as prostaglandins, sphingomyelinase, and a cysteine protease inhibitor are reported to be vital in shaping the innate immune response by inducing TH2 profile (Alarcon-Chaidez et al., 2009; Oliveira et al., 2011; Carvalho-Costa et al., 2015; Lieskovská et al., 2015). Another study also reports that shifting of host immune response towards $\mathrm{TH} 2$ leads to stimulation of the humoral immune response and promotes B cell proliferation and induction of antibody production (Berger, 2000). Various studies report that repeated infestation of mice with ticks increases the level of TGF- $\beta$ and leads to gradual increase in level of IL-10, IL-4 as well as increased TH2 response (Alarcon-Chaidez et al., 2009, Ferreira and Silva, 1999). During tick feeding, differential expression of salivary molecules which are capable of reducing proinfmammatory cytokines such as IL-12, IL-1 $\beta$ or TNF- $\alpha$ as well as production of anti-infmammatory mediators i.e IL-10. All 
of these events mentioned earlier further contributes towards maintenance of skewed $\mathrm{TH} 2$ immune response and contribute to AGS development (Ferreira and Silva, 1999).

Review including key details related to tick bite development of $B$ cells in context AGS can be found elsewhere (Chandrasekhar et al., 2020). Briefly, the initial encounter of allergen with host immune cells happens at the skin epithelium during the tick bite. It is reported that tick saliva contains high concentration of Prostaglandin E2 $\left(\mathrm{PGE}_{2}\right)$, which is found to be involved in reduction of inflammation and recruitment of macrophages. Hence, these events help further to create a suitable environment to drive immune response towards TH2 profile (Williams, 1979; Poole et al., 2013). Additionally, research has shown that $\mathrm{PGE}_{2}$ can directly induce class switching of the specific B cells to produce IgE (Gao et al., 2016). The development of $\mathrm{B}$ cell-producing antigen-specific $\operatorname{IgE} \mathrm{Abs}$ is a hallmark of allergic responses following antigen exposure. CabezasCruz and Valdes (2014) reported that tick saliva induces responses like a venom antigen, which not only counteracts with the immune system but also drives immune sensitization. Initial encounter between tick-secreted saliva antigen and host immune cells happens at the skin epithelium during a tick bite. Antigen presenting cells (APCs) present in skin more specifically, Langerhans cells (LCs) and dendritic cells (DCs) recognize, capture, and process salivary $\alpha$-gal antigens and migrate to skin-draining lymph nodes to participate in sensitization of B cells (Figure 2) (Chandrasekhar et al., 2020). After clonal selection, sensitized B cells migrate to the tick bite site in the skin to manifest allergic responses by presenting the antigen to $\mathrm{T}$ cells, secreting proinflammatory cytokines, and $\alpha$-gal-specific antibodies that eventually trigger mast and basophil cell activation (Chandrasekhar et al., 2020).

During AGS development and allergic response various human cells are involved. In early sensitization stage skin resident antigen presenting cells are vital. Skin is compartmentalized into two layers i.e., epidermis and dermis by basement membrane. In these layers specialized antigen presenting cells (APCs) namely Langerhans cells, a subpopulation of Dendritic cells (DC) are present. DCs play central role in connecting both innate and adaptive immune systems. Especially in context of tick bite and sensitization these cells are involved in internalization and processing of $\alpha$-gal bound antigens injected by tick while feeding (Kashem et al., 2017). Since, DCs do not produce cytokines required for TH2 cell differentiation for the development of AGS, tick salivary component like PGE2 are required to polarize DCs towards TH2 (Carvalho-Costa et al., 2015). After completion of sensitization, mast cells play central role in allergic response. Mast cells are localized in tissue and express IgE binding receptors (FceRI). During activation stage cross linking of FceRI bound IgE Abs occurs that leads to degranulation of mast cells to release allergy specific mediators along with $\mathrm{TH} 2$ cytokines (i.e., IL-3, IL-4) (Mcleod et al., 2015).

Basophils are important circulating granulocytes, which are involved in chronic allergic responses as well as tick acquired resistance in non-natural hosts (Sokol et al., 2009; Karasuyama et al., 2020). Like mast cells basophil cells also express FceRI receptors to bind $\operatorname{IgE}$ and release histamine and related mediators after activation and degranulation (Sokol et al., 2009). In addition, that study suggests basophils might be involved in antigen presentation and initiation of $\mathrm{TH} 2$ immune response and cytokine production (Sokol et al., 2009).

\section{CONCLUSIONS}

AGS is a newly emerged food allergy reported in different parts of the world and is associated with tick bites. The $\alpha$-gal epitope (galactose- $\alpha$-1,3-galactose), an oligosaccharide, is the prime culprit responsible for AGS. The exact mechanism of how a tick bite causes human sensitization against $\alpha$-gal and leads to the development of AGS, is poorly understood. Identification and functional characterization of tick-associated molecules are vital for developing interventions to prevent and control this disease. The presence of the $\alpha$-gal epitope in tick species has been confirmed. However, mechanism of synthesis, origin and delivery of these molecules at the tick-host interface are subject of investigation. Furthermore, there is a gap in our understanding of how tick microbiome contributes towards AGS development. Comparative analysis of the microbiomes maintained by the ticks along with their genetic machinery using genomic and transcriptomic approaches may reveal the genes contributing to $\alpha$-gal synthesis. Future research should be focused on 1) identifying and characterizing key tick salivary molecules decorated with the $\alpha$ gal epitope, 2) the molecular mechanism of $\alpha$-gal synthesis, 3 ) the mechanism of $\alpha$-gal delivery in tick-host interaction interface, 4 ) the process of sensitization against $\alpha$-gal during tick hematophagy and involved immune pathways, and 5) the role of various hostassociated and tick-associated factors contributing to the development of AGS.

\section{AUTHOR CONTRIBUTIONS}

SRS searched the literature and wrote the initial draft of manuscript. SK searched the literature and wrote the manuscript. All authors contributed to the article and approved the submitted version.

\section{FUNDING}

This work was supported by USDA National Institute of Food and Agriculture awards, 2017-67017-26171 and 2016-6703024576; the National Institutes of Allergy and Infectious Diseases award, RO1 AI135049; and the National Institutes of General Medical Sciences award, P20RR016476.

\section{SUPPLEMENTARY MATERIAL}

The Supplementary Material for this article can be found online at: https://www.frontiersin.org/articles/10.3389/fcimb.2021. 680264/full\#supplementary-material

Supplementary Figure 1 | Distribution of tick species known to be associated with alpha-gal syndrome.

Supplementary Figure 2 | Summary of Alpha-gal Sensitization and associated symptoms. 


\section{REFERENCES}

Adrion, E. R., Aucott, J., Lemke, K. W., and Weiner, J. P. (2015). Health Care Costs, Utilization and Patterns of Care Following Lyme Disease. PloS One 10 (2), e0116767. doi: 10.1371/journal.pone.0116767

Alarcon-Chaidez, F. J., Boppana, V. D., Hagymasi, A. T., Adler, A. J., and Wikel, S. K. (2009). A Novel Sphingomyelinase-Like Enzyme in Ixodes Scapularis Tick Saliva Drives Host CD4 + T Cells to Express IL-4. Parasite Immunol. 31 (4), 210-219. doi: 10.1111/j.1365-3024.2009.01095.x

Alpha-gal information (2020). Available at: https://alphagalinformation.org/.

Alpha-Gal Syndrome Subcommittee Report to the TBDWG | HHS.gov (n.d). Available at: https://www.hhs.gov/ash/advisory-committees/tickbornedisease/ reports/alpha-gal-subcomm-2020/index.html.

Apostolovic, D., Mihailovic, J., Commins, S. P., Wijnveld, M., Kazimirova, M., Starkhammar, M., et al. (2020). Allergenomics of the Tick Ixodes Ricinus Reveals Important $\alpha$-Gal-Carrying IgE-Binding Proteins in Red Meat Allergy. Allergy 75 (1), 217-220. doi: 10.1111/all.13978

Apostolovic, D., Tran, T. A. T., Hamsten, C., Starkhammar, M., Cirkovic Velickovic, T., and Van Hage, M. (2014). Immunoproteomics of Processed Beef Proteins Reveal Novel Galactose- $\alpha-1,3$-Galactose-Containing Allergens. Allergy 69 (10), 1308-1315. doi: 10.1111/all.12462

Araujo, R. N., Franco, P. F., Rodrigues, H., Santos, L. C. B., McKay, C. S., Sanhueza, C. A., et al. (2016). Amblyomma Sculptum Tick Saliva: $\alpha$-Gal Identification, Antibody Response and Possible Association With Red Meat Allergy in Brazil. Int. J. Parasitol. 46 (3), 213-220. doi: 10.1016/j.ijpara.2015.12.005

Avila, J. L., Rojas, M., and Galili, U. (1989). Immunogenic Gal Alpha 1-3 Gal Carbohydrate Epitopes are Present on Pathogenic American Trypanosoma and Leishmania. J. Immunol. 142 (8), 2828-2834.

Berends, A., and Oude Elberink, J. N. (2017). Het Alfa-Galsyndroom, Allergische Reacties Op Vlees [The Alpha-Gal Syndrome: An Allergic Reaction to Mammalian Meat Secondary to a Tick Bite]. Nederlands Tijdschrift voor Geneeskunde 161, D1062.

Berger, A. (2000). Th1 and Th2 Responses: What are They? BMJ 321 (7258):424. doi: $10.1136 / \mathrm{bmj} .321 .7258 .424$

Binder, A. M., Commins, S. P., Altrich, M. L., Wachs, T., Biggerstaff, B. J., Beard, C. B., et al. (2021). Diagnostic Testing for Galactose-Alpha-1,3-Galactose, United Stateto 2018. Ann. Allergy Asthma Immunol. 126 (4), 411-416.e1. doi: 10.1016/ j.anai.2020.12.019

Bircher, A. J., Hofmeier, K. S., Link, S., and Heijnen, I. (2017). Food Allergy to the Carbohydrate Galactose-Alpha-1,3-Galactose (Alpha-Gal): Four Case Reports and a Review. Eur. J. Dermatol. 27 (1), 3-9. doi: 10.1684/ejd.2016.2908

Bonnet, S. I., Binetruy, F., Hernández-Jarguín, A. M., and Duron, O. (2017). The Tick Microbiome: Why Non-Pathogenic Microorganisms Matter in Tick Biology and Pathogen Transmission. . Front. Cell. Infect. Microbiol. 7:236. doi: $10.3389 /$ fcimb.2017.00236

Brites-Neto, J., Duarte, K. M. R., and Martins, T. F. (2015). Tick-Borne Infections in Human and Animal Population Worldwide. Vet. World 8 (3), 301-315. doi: 10.14202/vetworld.2015.301-315

Brown, D. B., Muszynski, A., and Carlson, R. W. (2013). Elucidation of a Novel Lipid A $\alpha-(1,1)$-GalA Transferase Gene (Rgtf) From Mesorhizobium Loti: Heterologous Expression of rgtF Causes Rhizobium Etli to Synthesize Lipid A With $\alpha-(1,1)-G a l A$. Glycobiology 23 (5), 546-558. doi: 10.1093/glycob/cws223

Bullard, R., Sharma, S. R., Das, P., Morgan, S., and Karim, S. (2019). Repurposing of Glycine-Rich Proteins in Abiotic and Biotic Stresses in the Lone-Star Tick (Amblyomma Americanum). Front. Physiol. 10:744. doi: 10.3389/FPHYS.2019.00744

Cabezas-Cruz, A., and Valdés, J. J. (2014). Are Ticks Venomous Animals? Fronti. Zool 11, 47. doi: 10.1186/1742-9994-11-47

Cabezas-Cruz, A., Espinosa, P. J., Alberdi, P., Šimo, L., Valdés, J. J., MateosHernández, L., et al. (2018). Tick Galactosyltransferases Are Involved in $\alpha$-Gal Synthesis and Play a Role During Anaplasma Phagocytophilum Infection and Ixodes Scapularis Tick Vector Development. Sci. Rep. 8 (1), 14224. doi: 10.1038/s41598-018-32664-z

Cabezas-Cruz, A., Hodžić, A., Román-Carrasco, P., Mateos-Hernández, L., Duscher, G. G., Sinha, D. K., et al. (2019). Environmental and Molecular Drivers of the $\alpha$-Gal Syndrome. Front. Immunol. 10:1210. doi: 10.3389/fimmu.2019.01210

Calamari, A. M., Poppa, M., Villalta, D., and Pravettoni, V. (2015). Alpha-Gal Anaphylaxis: The First Case Report in Italy. Eur. Ann. Allergy Clin. Immunol. 47 (5), 161-162.
Caponetto, P., Fischer, J., and Biedermann, T. (2013). Gelatin-Containing Sweets Can Elicit Anaphylaxis in a Patient With Sensitization to Galactose- $\alpha-1,3-$ Galactose. J. Allergy Clin. Immunol.: In Pract. 1 (3), 302-303. doi: 10.1016/ j.jaip.2013.01.007

Carvalho-Costa, T. M., Mendes, M. T., Silva, M. D., Costa, T. D., Tiburcio, M., Anhê, A., et al. (2015). Immunosuppressive Effects of Amblyomma Cajennense Tick Saliva on Murine Bone Marrow-Derived Dendritic Cells. Parasites Vectors 8 (1), 22. doi: 10.1186/s13071-015-0634-7

Chandrasekhar, J. L., Cox, K. M., and Erickson, L. D. (2020). B Cell Responses in the Development of Mammalian Meat Allergy. Front. Immunol. 11:1532. doi: 10.3389/fimmu.2020.01532

Chinuki, Y., Ishiwata, K., Yamaji, K., Takahashi, H., and Morita, E. (2016). Haemaphysalis Longicornis Tick Bites Are a Possible Cause of Red Meat Allergy in Japan. Allergy 71 (3), 421-425. doi: 10.1111/all.12804

Chmelař, J., Kotál, J., Kopecký, J., Pedra, J. H. F., and Kotsyfakis, M. (2016). All for One and One for All on the Tick-Host Battlefield. Trends Parasitol. 32 (5), 368-377. doi: 10.1016/j.pt.2016.01.004

Chung, C. H., Mirakhur, B., Chan, E., Le, Q.-T., Berlin, J., Morse, M., et al. (2008). Cetuximab-Induced Anaphylaxis and IgE Specific for Galactose- $\alpha-1,3-$ Galactose. New Engl. J. Med. 358 (11), 1109-1117. doi: 10.1056/nejmoa074943 Commins, S. P. (2015). Mechanisms of Oral Tolerance. Pediatr. Clinics North America 62 (6), 1523-1529. doi: 10.1016/j.pcl.2015.07.013

Commins, S. P. (2016). Invited Commentary: Alpha-Gal Allergy: Tip of the Iceberg to a Pivotal Immune Response. Curr. Allergy Asthma Rep. 16, 61. doi: 10.1007/s11882-016-0641-6

Commins, S. P. (2020). Diagnosis \& Management of Alpha-Gal Syndrome: Lessons From 2,500 Patients. Expert Rev. Clin. Immunol. 16 (7), 667-677. doi: 10.1080/1744666X.2020.1782745

Commins, S. P., James, H. R., Kelly, L. A., Pochan, S. L., Workman, L. J., Perzanowski, M. S., et al. (2011). The Relevance of Tick Bites to the Production of IgE Antibodies to the Mammalian Oligosaccharide Galactose- $\alpha-1,3-$ Galactose. J. Allergy Clin. Immunol. 127 (5), 1286-1293.e6. doi: 10.1016/j.jaci.2011.02.019

Commins, S. P., Jerath, M. R., Cox, K., Erickson, L. D., and Platts-Mills, T. (2016). Delayed Anaphylaxis to Alpha-Gal, an Oligosaccharide in Mammalian Meat. Allergol. Int. 65 (1), 16-20. doi: 10.1016/j.alit.2015.10.001

Commins, S. P., Kelly, L. A., Rönmark, E., James, H. R., Pochan, S. L., Peters, E. J., et al. (2012). Galactose- $\alpha-1,3-$ Galactose-Specific IgE Is Associated With Anaphylaxis But Not Asthma. Am. J. Respir. Crit. Care Med. 185 (7), $723-$ 730. doi: $10.1164 / \mathrm{rccm} .201111-2017 \mathrm{OC}$

Commins, S. P., and Platts-Mills, T. A. E. (2013a). Delayed Anaphylaxis to Red Meat in Patients With IgE Specific for Galactose Alpha-1,3-Galactose (AlphaGal). Curr. Allergy Asthma Rep. 13 (1), 72-77. doi: 10.1007/s11882-012-0315-y

Commins, S. P., and Platts-Mills, T. A. E. (2013b). Tick Bites and Red Meat Allergy. Curr. Opin. Allergy Clin. Immunol. 13 (4), 354-359. doi: 10.1097/ ACI.0b013e 3283624560

Commins, S. P., Satinover, S. M., Hosen, J., Mozena, J., Borish, L., Lewis, B. D., et al. (2009). Delayed Anaphylaxis, Angioedema, or Urticaria After Consumption of Red Meat in Patients With IgE Antibodies Specific for Galactose- $\alpha-1,3-$ Galactose. J. Allergy Clin. Immunol. 123 (2), 426-433. doi: 10.1016/j.jaci.2008.10.052

Crispell, G., Commins, S., Archer-Hartmann, S. A., Choudhary, S., Dharmarajan, G., Azadi, P., et al. (2019). Discovery of Alpha-Gal-Containing Antigens in North American Tick Species Believed to Induce Red Meat Allergy. Front. Immunol. 10:1056. doi: 10.3389/FIMMU.2019.01056

De Pourcq, K., De Schutter, K., and Callewaert, N. (2010). Engineering of Glycosylation in Yeast and Other Fungi: Current State and Perspectives. Appl. Microbiol. Biotechnol. 87 (5), 1617-1631. doi: 10.1007/s00253-0102721-1

Facts and Statistics | Food Allergy Research \& Education (2019). Available at: https://www.foodallergy.org/life-with-food-allergies/food-allergy-101/factsand-statistics.

Ferreira, B. R., and Silva, J. S. (1999). Successive Tick Infestations Selectively Promote a T-Helper 2 Cytokine Profile in Mice. Immunology 96 (3), 434-439. doi: $10.1046 / j .1365-2567.1999 .00683 . x$

Fischer, J., Hebsaker, J., Caponetto, P., Platts-Mills, T. A. E., and Biedermann, T. (2014). Galactose-Alpha-1,3-Galactose Sensitization is a Prerequisite for PorkKidney Allergy and Cofactor-Related Mammalian Meat Anaphylaxis. J. Allergy Clin. Immunol. 134 (3), 755-759.e1. doi: 10.1016/j.jaci.2014.05.051 
Fischer, J., Lupberger, E., Hebsaker, J., Blumenstock, G., Aichinger, E., Yazdi, A. S., et al. (2017). Prevalence of Type I Sensitization to Alpha-Gal in Forest Service Employees and Hunters. Allergy 72 (10), 1540-1547. doi: 10.1111/all.13156

Fischer, J., Yazdi, A. S., and Biedermann, T. (2016). Clinical Spectrum of $\alpha$-Gal Syndrome: From Immediate-Type to Delayed Immediate-Type Reactions to Mammalian Innards and Meat. Allergo J. Int. 25 (2), 55-62. doi: 10.1007/ s40629-016-0099-z

Francischetti, I. M. (2010). Platelet Aggregation Inhibitors From Hematophagous Animals. Toxicon 56 (7), 1130-1144. doi: 10.1016/j.toxicon.2009.12.003

Francischetti, I. M., Sa-Nunes, A., Mans, B. J., Santos, I. M., and Ribeiro, J. M. (2009). The Role of Saliva in Tick Feeding. Front. Biosci. (Landmark edition) 14, 2051-2088. doi: 10.2741/3363

Galili, U. (2001). The $\alpha$-Gal Epitope (Gal $\alpha 1-3$ gal $\beta 1-4$ glcnac-R) in Xenotransplantation. Biochimie 83 (7), 557-563. doi: 10.1016/s0300-9084 (01)01294-9

Galili, U. (2005). The Alpha-Gal Epitope and the Anti-Gal Antibody in Xenotransplantation and in Cancer Immunotherapy. Immunol. Cell Biol. 83 (6), 674-686. doi: 10.1111/j.1440-1711.2005.01366.x

Galili, U. (2013a). Discovery of the Natural Anti-Gal Antibody and its Past and Future Relevance to Medicine. Xenotransplantation 20 (3), 138-147. doi: $10.1111 /$ xen. 12034

Galili, U. (2013b). Anti-Gal: An Abundant Human Natural Antibody of Multiple Pathogeneses and Clinical Benefits. Immunology 140 (1), 1-11. doi: 10.1111/ imm. 12110

Galili, U. (2015). Significance of the Evolutionary $\alpha 1,3$-Galactosyltransferase (GGTA1) Gene Inactivation in Preventing Extinction of Apes and Old World Monkeys. J. Mol. Evol. 80 (1), 1-9. doi: 10.1007/s00239-014-9652-x

Galili, U. (2020). Amplifying Immunogenicity of Prospective Covid-19 Vaccines by Glycoengineering the Coronavirus Glycan-Shield to Present $\alpha$-Gal Epitopes. Vaccine 38 (42), 6487-6499. doi: 10.1016/j.vaccine.2020.08.032

Galili, U., Anaraki, F., Thall, A., Hill-Black, C., and Radic, M. (1993). One Percent of Human Circulating B Lymphocytes are Capable of Producing the Natural Anti-Gal Antibody. Blood 82 (8), 2485-2493. doi: 10.1182/blood.v82.8. 2485.bloodjournal 8282485

Galili, U., and Avila, J. L. (Eds.) (1999). $\alpha$-Gal and Anti-Gal, $\alpha 1,3-$ Galactosyltransferase, $\alpha$-Gal Epitopes, and the Natural Anti-Gal Antibody Subcellular Biochemistry Vol. 32 (Boston, MA: Springer US). doi: 10.1007/ 978-1-4615-4771-6

Galili, U., Mandrell, R. E., Hamadeh, R. M., Shohet, S. B., and Griffiss, J. M. (1988). Interaction Between Human Natural Anti- $\alpha$-Galactosyl Immunoglobulin G and Bacteria of the Human Flora. Infect. Immun. 56 (7), 1730-1737. doi: 10.1128/iai.56.7.1730-1737.1988

Galili, U., Rachmilewitz, E. A., Peleg, A., and Flechner, I. (1984). A Unique Natural Human IgG Antibody With Anti- $\alpha$-Galactosyl Specificity. J. Exp. Med. 160 (5), 1519-1531. doi: 10.1084/jem.160.5.1519

Gao, Y., Zhao, C., Wang, W., Jin, R., Li, Q., Ge, Q., et al. (2016). Prostaglandins E2 Signal Mediated by Receptor Subtype EP2 Promotes IgE Production In Vivo and Contributes to Asthma Development. Sci. Rep. 6, 20505. doi: 10.1038/ srep20505

Ginsberg, H. S., Hickling, G. J., Burke, R. L., Ogden, N. H., Beati, L., LeBrun,, R. A., et al. (2021). Why Lyme Disease Is Common In The Northern US, But Rare In The South: The Roles Of Host Choice, Host-Seeking Behavior, And Tick Density. PLoS biology 19 (1), e3001066. doi: 10.1371/journal.pbio.3001066

Glatz, M., Means, T., Haas, J., Steere, A. C., and Müllegger, R. R. (2017). Characterization of the Early Local Immune Response to Ixodes Ricinus Tick Bites in Human Skin. Exp. Dermatol. 26 (3), 263-269. doi: 10.1111/exd.13207

Gonzalez-Quintela, A., Dam Laursen, A. S., Vidal, C., Skaaby, T., Gude, F., and Linneberg, A. (2014). IgE Antibodies to Alpha-Gal in the General Adult Population: Relationship With Tick Bites, Atopy, and Cat Ownership. Clin. Exp. Allergy 44 (8), 1061-1068. doi: 10.1111/cea.12326

Gowda, D. C., Glushka, J., Van Halbeek, H., Thotakura, R. N., Bredehorst, R., and Vogel, C. W. (2001). N-Linked Oligosaccharides of Cobra Venom Factor Novel $\alpha(1-3)$ Galactosylated Le ${ }^{\mathrm{X}}$ Structures. Glycobiology 11 (3), 195-208. doi: 10.1093/glycob/11.3.195

Graham-Rowe, D. (2011). Lifestyle: When Allergies Go West. Nature 479, S2-S4. doi: $10.1038 / 479 S 2 a$

Gray, C., Zyl, A. V., and Strauss, L. (2016). 'Midnight Anaphylaxis' to Red Meat in Patients With Alpha-Gal Sensitisation: A Recent Discovery in the Food Allergy
World and a Case Report From South Africa: Guest Review. Curr. Allergy Clin. Immunol. 29, 102-104.

Guillier, A., Fauconneau, A., De Barruel, F., Guez, S., and Doutre, M. S. (2015). Allergic Hypersensitivity to Red Meat Induced by Tick Bites: A French Case Report. Eur. J. Dermatol. 25 (3), 277. doi: 10.1684/ejd.2015.2531

Hamadeh, R. M., Jarvis, G. A., Zhou, P., Cotleur, A. C., and Griffiss, J. M. (1996). Bacterial Enzymes can Add Galactose Alpha 1,3 to Human Erythrocytes and Creates a Senescence-Associated Epitope. Infect. Immun. 64 (2), 528-534. doi: 10.1128/iai.64.2.528-534.1996

Hamsten, C., Starkhammar, M., Tran, T. A. T., Johansson, M., Bengtsson, U., Ahlén, G., et al. (2013). Identification of Galactose- $\alpha-1,3$-Galactose in the Gastrointestinal Tract of the Tick Ixodes Ricinus; Possible Relationship With Red Meat Allergy. Allergy 68 (4), 549-552. doi: 10.1111/all.12128

Hamsten, C., Tran, T. A. T., Starkhammar, M., Brauner, A., Commins, S. P., Platts-Mills, T. A. E., et al. (2013). Red Meat Allergy in Sweden: Association With Tick Sensitization and B-Negative Blood Groups. J. Allergy Clin. Immunol. 132 (6), 1431-1434.e6. doi: 10.1016/j.jaci.2013.07.050

Hashizume, H., Fujiyama, T., Umayahara, T., Kageyama, R., Walls, A. F., and Satoh, T. (2018). Repeated Amblyomma Testudinarium Tick Bites are Associated With Increased Galactose- $\alpha-1,3$-Galactose Carbohydrate IgE Antibody Levels: A Retrospective Cohort Study in a Single Institution. J. Am. Acad. Dermatol. 78 (6), 1135-1141.e3. doi: 10.1016/j.jaad.2017.12.028

Hendricks, S. P., He, P., Stults, C. L., and Macher, B. A. (1990). Regulation of the Expression of Gal Alpha 1-3Gal Beta 1-4glcnac Glycosphingolipids in Kidney. J. Biol. Chem. 265 (29), 17621-17626. doi: 10.1016/s0021-9258

Hilger, C., Fischer, J., Swiontek, K., Hentges, F., Lehners, C., Eberlein, B., et al. (2016a). Two Galactose- $\alpha-1,3-$ Galactose Carrying Peptidases From Pork Kidney Mediate Anaphylactogenic Responses in Delayed Meat Allergy. Allergy 71 (5), 711-719. doi: 10.1111/all.12835

Hodžić, A., Mateos-Hernández, L., Fréalle, E., Román-Carrasco, P., Alberdi, P., Pichavant, M., et al. (2016). Infection With Inhibits the Production of IgE Antibodies to $\alpha$-Gal in Humans: Towards a Conceptual Framework of the Hygiene Hypothesis? Vaccines 20208 (2), 167. doi: 10.3390/vaccines802016

Hodžić, A., Mateos-Hernández, L., Leschnik, M., Alberdi, P., Rego, R., Contreras, M., et al. (2019). Tick Bites Induce Anti- $\alpha$-Gal Antibodies in Dogs. Vaccines 7 (3), 114. doi: 10.3390/vaccines 7030114

Iniguez, E., Schocker, N. S., Subramaniam, K., Portillo, S., Montoya, A. L., AlSalem, W. S., et al. (2017). An $\alpha$-Gal-Containing Neoglycoprotein-Based Vaccine Partially Protects Against Murine Cutaneous Leishmaniasis Caused by Leishmania Major. PloS Neglect. Trop. Dis. 11 (10), e0006039. doi: 10.1371/ journal.pntd.0006039

Iweala, O., Brennan, P. J., and Commins, S. P. (2017). Serum IgE Specific for Alpha-Gal Sugar Moiety can Bind Glycolipid. J. Allergy Clin. Immunol. 139 (2), AB88. doi: 10.1016/j.jaci.2016.12.237

Iweala, O. I., Choudhary, S. K., Addison, C. T., Batty, C. J., Kapita, C. M., Amelio, C., et al. (2020). Glycolipid-Mediated Basophil Activation in Alpha-Gal Allergy. J. Allergy Clin. Immunol. 146 (2), 450-452. doi: 10.1016/ j.jaci.2020.02.006

Iweala, O. I., Choudhary, S. K., and Commins, S. P. (2018). Food Allergy. Curr. Gastroenterol. Rep. 20 (5), 17. doi: 10.1007/s11894-018-0624-y

Iweala, O. I., and Nagler, C. R. (2019). The Microbiome and Food Allergy. Annu. Rev. Immunol. 37 (1), 377-403. doi: 10.1146/annurev-immunol-042718041621

Jacquenet, S., Moneret-Vautrin, D. A., and Bihain, B. E. (2009). Mammalian MeatInduced Anaphylaxis: Clinical Relevance of Anti-Galactose-Alpha-1,3Galactose IgE Confirmed by Means of Skin Tests to Cetuximab. J. Allergy Clin. Immunol. 124 (3), 603-605. doi: 10.1016/j.jaci.2009.06.014

Jappe, U. (2014). Anaphylaxie Durch Versteckte Nahrungsmittelallergene: Das $\alpha-$ Gal Syndrom Allergologie 37, 265-274. doi: 10.5414/ALX01667

Jongejan, F., and Uilenberg, G. (2004). The Global Importance of Ticks. Parasitology 129, S3-S14. doi: 10.1017/S0031182004005967

Justiz Vaillant, A. A., Vashisht, R., and Zito, P. M. (2021). "Immediate Hypersensitivity Reactions," in StatPearls (Treasure Island, FL: StatPearls Publishing).

Kaloga, M., Kourouma, S., Kouassi, Y. I., Ecra, E. J., Gbery, I. P., Allou, A. S., et al. (2016). Allergy to Red Meat: A Diagnosis Made by the Patient and Confirmed by an Assay for IgE Antibodies Specific for Alpha-1,3-Galactose. Case Rep. Dermatol. 8 (1), 10-13. doi: 10.1159/000443631 
Karasuyama, H., Miyake, K., and Yoshikawa, S. (2020). Immunobiology of Acquired Resistance to Ticks. Front. Immunol. 11, 601504. doi: 10.3389/ fimmu.2020.601504

Kashem, S. W., Haniffa, M., and Kaplan, D. H. (2017). Antigen-Presenting Cells in the Skin. Annu. Rev. Immunol. 35, 469-499. doi: 10.1146/annurev-immunol051116-052215

Kazimírová, M., and Štibrániová, I. (2013). Tick Salivary Compounds: Their Role in Modulation of Host Defences and Pathogen Transmission. Front. Cell. Infect. Microbiol. 3:43. doi: 10.3389/fcimb.2013.00043

Keleş, Ş., and Gündüz, M. (2019). Alpha Gal Specific IgE Positivity Due to Tick Bites and Red Meat Allergy: The First Case Report in Turkey. Turkish J. Pediatr. 61 (4), 615-617. doi: 10.24953/turkjped.2019.04.023

Khoury, J. K., Khoury, N. C., Schaefer, D., Chitnis, A., and Hassen, G. W. (2018). A Tick-Acquired Red Meat Allergy. Am. J. Emergency Med. 36 (2), 341.e1-341.e3. doi: 10.1016/j.ajem.2017.10.044

Kotál, J., Langhansová, H., Lieskovská, J., Andersen, J. F., Francischetti, I. M. B., Chavakis, T., et al. (2015). Modulation of Host Immunity by Tick Saliva. J. Proteomics 128, 58-68. doi: 10.1016/j.jprot.2015.07.005

Krzyszczyk, P., Schloss, R., Palmer, A., and Berthiaume, F. (2018). The Role of Macrophages in Acute and Chronic Wound Healing and Interventions to Promote Pro-Wound Healing Phenotypes. Front. Physiol. 9:419. doi: 10.3389/ fphys.2018.00419

Lantéri, M., Giordanengo, V., Vidal, F., Gaudray, P., and Lefebvre, J. C. (2002). A Complete $\alpha 1,3$-Galactosyltransferase Gene is Present in the Human Genome and Partially Transcribed. Glycobiology 12 (12), 785-792. doi: 10.1093/glycob/ cwf087

Lee, J. H., Kim, J. H., Kim, T. H., and Kim, S. C. (2013). Delayed Mammalian Meat-Induced Anaphylaxis Confirmed by Skin Test to Cetuximab. J. Dermatol. 40 (7), 577-578. doi: 10.1111/1346-8138.12140

Lied, G. A. (2017). Red Meat Allergy Induced by Tick Bites: A Norwegian Case Report. Eur. Ann. Allergy Clin. Immunol. 49 (4), 186-188. doi: 10.23822/ eurannaci.1764-1489.04

Lieskovská, J., Páleníková, J., Širmarová, J., Elsterová, J., Kotsyfakis, M., Campos Chagas, A., et al. (2015). Tick Salivary Cystatin Sialostatin L2 Suppresses IFN Responses in Mouse Dendritic Cells. Parasite Immunol. 37 (2), 70-78. doi: $10.1111 /$ pim.12162

Loh, W., and Tang, M. (2018). The Epidemiology of Food Allergy in the Global Context. Int. J. Environ. Res. Public Health 15 (9), 2043. doi: 10.3390/ ijerph15092043

Macher, B. A., and Galili, U. (2008). The Gal $\alpha 1,3$ gal $\beta 1,4$ glcnac-R ( $\alpha-G a l)$ Epitope: A Carbohydrate of Unique Evolution and Clinical Relevance. Biochim. Biophys. Acta 1780 (2), 75-88. doi: 10.1016/j.bbagen.2007.11.003

Maldonado-Ruiz, L. P., Neupane, S., Park, Y., and Zurek, L. (2021). The Bacterial Community of the Lone Star Tick (Amblyomma Americanum). Parasites Vectors 14, 49. doi: 10.1186/s13071-020-04550-z

Mans, B. J. (2011). Evolution of Vertebrate Hemostatic and Inflammatory Control Mechanisms in Blood-Feeding Arthropods. J. Innate Immun. 3 (1), 41-51. doi: 10.1159/000321599

Mateos-Hernández, L., Villar, M., Moral, A., Rodríguez, C. G., Arias, T. A., de la Osa, V., et al. (2017). Tick-Host Conflict: Immunoglobulin E Antibodies to Tick Proteins in Patients With Anaphylaxis to Tick Bite. Oncotarget 8 (13), 20630-20644. doi: 10.18632/oncotarget.15243

Mcleod, J. J., Baker, B., and Ryan, J. J. (2015). Mast Cell Production and Response to IL-4 and IL-13. Cytokine 75, 57-61. doi: 10.1016/j.cyto.2015.05.019

Michel, S., Scherer, K., Heijnen, I. A., and Bircher, A. J. (2014). Skin Prick Test and Basophil Reactivity to Cetuximab in Patients With IgE to Alpha-Gal and Allergy to Red Meat. Allergy 69 (3), 403-405. doi: 10.1111/all.12344

Montassier, E., Al-Ghalith, G. A., Mathé, C., Le Bastard, Q., Douillard, V., Garnier, A., et al. (2019). Distribution of Bacterial $\alpha 1,3$-Galactosyltransferase Genes in the Human Gut Microbiome. Front. Immunol. 10:3000. doi: 10.3389/ fimmu.2019.03000

Monzón, J. D., Atkinson, E. G., Henn, B. M., and Benach, J. L. (2016). Population and Evolutionary Genomics of Amblyomma Americanum, an Expanding Arthropod Disease Vector. Genome Biol. Evol. 8 (5), 1351-1360. doi: 10.1093/gbe/evw080

Morisset, M., Richard, C., Astier, C., Jacquenet, S., Croizier, A., Beaudouin, E., et al. (2012). Anaphylaxis to Pork Kidney Is Related to IgE Antibodies Specific for Galactose-Alpha-1,3-Galactose. Allergy 67 (5), 699-704. doi: 10.1111/ j.1398-9995.2012.02799.x
Moura, A. P. V., Santos, L. C. B., Brito, C. R. N., Valencia, E., Junqueira, C., Filho, A. A. P., et al. (2017). Virus-Like Particle Display of the $\alpha$-Gal Carbohydrate for Vaccination Against Leishmania Infection. ACS Cent. Sci. 3 (9), 1026-1031. doi: 10.1021/acscentsci.7b00311

Mullins, R. J., James, H., Platts-Mills, T. A., and Commins, S. (2012). Relationship Between Red Meat Allergy and Sensitization to Gelatin and Galactose- $\alpha-1,3-$ Galactose. J. Allergy Clin. Immunol. 129 (5), 1334-1342.e1. doi: 10.1016/ j.jaci.2012.02.0

Ohshima, Y. (2013). Mucosal Immunity and the Onset of Allergic Disease. Allergol. Int. 62 (3), 279-289. doi: 10.2332/allergolint.13-RAI-0585

Oliveira, C. J. F., Sá-Nunes, A., Francischetti, I. M. B., Carregaro, V., Anatriello, E., Silva, J. S., et al. (2011). Deconstructing Tick Saliva: Non-Protein Molecules With Potent Immunomodulatory Properties. J. Biol. Chem. 286 (13), 1096010969. doi: 10.1074/jbc.M110.205047

Parola, P., and Raoult, D. (2001). Ticks and Tick-Borne Bacterial Diseases in Humans: An Emerging Infectious Threat. Clin. Infect. Dis. 32 (6), 897-928. doi: $10.1086 / 319347$

Pattanaik, D., Lieberman, P., Lieberman, J., Pongdee, T., and Keene, A. T. (2018). The Changing Face of Anaphylaxis in Adults and Adolescents. Ann. Allergy Asthma Immunol. 121 (5), 594-597. doi: 10.1016/j.anai.2018.07.017

Platts-Mills, T. A. E., Commins, S. P., Biedermann, T., van Hage, M., Levin, M., Beck, L. A., et al. (2020). On the Cause and Consequences of IgE to Galactose$\alpha-1,3-$ Galactose: A Report From the National Institute of Allergy and Infectious Diseases Workshop on Understanding IgE-Mediated Mammalian Meat Allergy. J. Allergy Clin. Immunol. 145, 1061-1071. doi: 10.1016/ j.jaci.2020.01.047

Platts-Mills, T. A. E., Schuyler, A. J., Hoyt, A. E. W., and Commins, S. P. (2015a). Delayed Anaphylaxis Involving IgE to Galactose-Alpha-1,3-Galactose. Curr. Allergy Asthma Rep. 15:12. doi: 10.1007/s11882-015-0512-6

Platts-Mills, T. A. E., Schuyler, A. J., Tripathi, A., and Commins, S. P. (2015b). Anaphylaxis to the Carbohydrate Side Chain Alpha-Gal. Immunol. Allergy Clinics North America 35 (2), 247-260. doi: 10.1016/j.iac.2015.01.009

Platts-Mills, T. A., and Commins, S. P. (2013). Emerging Antigens Involved In Allergic Responses. Current opinion in immunology 25 (6), 769-774. doi: 10.1016/j.coi.2013.09.002

Poole, N. M., Mamidanna, G., Smith, R. A., Coons, L. B., and Cole, J. A. (2013). Prostaglandin E2 in Tick Saliva Regulates Macrophage Cell Migration and Cytokine Profile. Parasites Vectors 6 (1), 261. doi: 10.1186/1756-3305-6-261

Posekany, K. J., Pittman, H. K., Bradfield, J. F., Haisch, C. E., and Verbanac, K. M. (2002). Induction of Cytolytic Anti-Gal Antibodies in $\alpha-1,3$ Galactosyltransferase Gene Knockout Mice by Oral Inoculation With Escherichia Coli O86:B7 Bacteria. Infect. Immun. 70 (11), 6215-6222. doi: 10.1128/IAI.70.11.6215-6222.2002

Posthumus, J., James, H., Wang, X., Commins, S., and Platts-Mills, T. A. E. (2010). Correlation of Blood Type With the Presence of IgE Antibodies to Galactose-Alpha1,3-Galactose (Alpha-Gal): Is There a Protective Effect of Blood Group Substance B? J. Allergy Clin. Immunol. 125 (2), AB203. doi: 10.1016/j.jaci.2009.12.795

Raghavan, R. K., Peterson, A. T., Cobos, M. E., Ganta, R., and Foley, D. (2019). Current and Future Distribution of the Lone Star Tick, Amblyomma Americanum (L.) (Acari: Ixodidae) in North America. PloS One 14 (1), e0209082. doi: 10.1371/journal.pone.0209082

Rochlin, I., and Toledo, A. (2020). Emerging Tick-Borne Pathogens of Public Health Importance: A Mini Review. J. Med. Microbiol. 69 (6), 781-791. doi: $10.1099 /$ jmm. 0.001206

Rosenberg, R., Lindsey, N. P., Fischer, M., Gregory, C. J., Hinckley, A. F., Mead, P. S., et al. (2018). Vital Signs: Trends in Reported Vectorborne Disease CasesUnited States and Territorie-2016. Morbid. Mortal. Wkly. Rep. 67 (17), 496501. doi: 10.15585/mmwr.mm6717e1

Savage, J., Sicherer, S., and Wood, R. (2016). The Natural History of Food Allergy. J. Allergy Clin. Immunol.: In Pract. 4 (2), 196-203. doi: 10.1016/j.jaip.2015.11.024 Schmidle, P., Reidenbach, K., Kugler, C., Eberlein, B., Biedermann, T., and Darsow, U. (2019). Recall Urticaria-a New Clinical Sign in the Diagnosis of Alpha-Gal Syndrome. J. Allergy Clin. Immunol. In Pract. 7 (2), 685-686. doi: 10.1016/j.jaip.2018.08.026

Schwan, T. G., and Piesman, J. (2002). Vector Interactions and Molecular Adaptations of Lyme Disease and Relapsing Fever Spirochetes Associated With Transmission by Ticks. Emerg. Infect. Dis. 8 (2), 115-121. doi: 10.3201/ eid0802.010198 
Schwartz, A. M., Kugeler, K. J., Nelson, C. A., Marx, G. E., and Hinckley, A. F. (2021). Use of Commercial Claims Data for Evaluating Trends in Lyme Disease Diagnoses, United State-2018. . Emerg. Infect. Dis. 27 (2), 499-507. doi: 10.3201/eid2702.202728

Sekiya, K., Fukutomi, Y., Nakazawa, T., Taniguchi, M., and Akiyama, K. (2012). Delayed Anaphylactic Reaction to Mammalian Meat. J. Invest. Allergol. Clin. Immunol. 22 (6), 446-447.

Shreiner, A., Kao, J. Y., and Young, V. B. (2015). The Gut Microbiome In Health And In Disease. Current opinion in gastroenterology 31 (1), 69-75. doi: 10.1097/MOG.0000000000000139w

Shreiner, A., Huffnagle, G. B., and Noverr, M. C. (2008). The "Microflora Hypothesis" of Allergic Disease. Adv. Exp. Med. Biol. 635, 113-134. doi: 10.1007/978-0-387-09550-9_10

Sim, D. W., Lee, J. S., Park, K. H., Jeong, K. Y., Ye, Y. M., Lee, J. H., et al. (2017). Accurate Assessment of Alpha-Gal Syndrome Using Cetuximab and Bovine Thyroglobulin-Specific IgE. Mol. Nutr. Food Res. 61 (10), 201601046. doi: 10.1002/mnfr.201601046

Soares, M. P., and Yilmaz, B. (2016). Microbiota Control of Malaria Transmission. Trends Parasitol. 32 (2), 120-130. doi: 10.1016/j.pt.2015.11.004

Socolovschi, C., Mediannikov, O., Raoult, D., and Parola, P. (2009). The Relationship Between Spotted Fever Group Rickettsiae and Ixodid Ticks. Vet. Res. 40 (2), 34. doi: 10.1051/vetres/2009017

Soh, J. Y., Huang, C. H., and Lee, B. W. (2015). Carbohydrates as Food Allergens. Asia Pac. Allergy 5 (1):17. doi: 10.5415/apallergy.2015.5.1.17

Sokol, C. L., Chu, N. Q., Yu, S., Nish, S. A., Laufer, T. M., and Medzhitov, R. (2009). Basophils Function as Antigen-Presenting Cells for an Allergen-Induced T Helper Type 2 Response. Nat. Immunol. 10 (7), 713-720. doi: 10.1038/ni.1738

Steinke, J. W., Platts-Mills, T. A., and Commins, S. P. (2015). The Alpha-Gal Story: Lessons Learned From Connecting the Dots. J. Allergy Clin. Immunol. 135 (3), 589-597. doi: 10.1016/j.jaci.2014.12.1947

Steinke, J. W., Pochan, S. L., James, H. R., Platts-Mills, T. A. E., and Commins, S. P. (2016). Altered Metabolic Profile in Patients With IgE to Galactose-Alpha-1,3Galactose Following In Vivo Food Challenge. J. Allergy Clin. Immunol. 138 (5), 1465-1467.e8. doi: 10.1016/j.jaci.2016.05.021

Takahashi, H., Chinuki, Y., Tanaka, A., and Morita, E. (2014a). Laminin $\gamma-1$ and Collagen $\alpha-1$ (VI) Chain are Galactose- $\alpha-1,3-$ Galactose-Bound Allergens in Beef. Allergy 69 (2), 199-207. doi: 10.1111/all.12302

Ticks and Mammalian Meat Allergy (2021). Available at: https://www.beefresearch. org/resources/beef-safety/fact-sheets/ticks-and-mammalian-meat-allergy.

Uasuf, C. G., Torina, A., Ferrantelli, V., and Brusca, I. (2018). An Unusual Case of Positive Sige to Galactose-Alpha-1,3-Galactose From South Italy. Eur. Ann. Allergy Clin. Immunol. 50 (1), 45-47. doi: 10.23822/EurAnnACI.1764-1489.25

van Nunen, S. (2014). Galactose-Alpha-1,3-Galactose, Mammalian Meat and Anaphylaxis: A World-Wide Phenomenon? Curr. Treat Options Allergy 1, 262-277. doi: 10.1007/s40521-014-0022-0

van Nunen, S. (2015). Tick-Induced Allergies: Mammalian Meat Allergy, Tick Anaphylaxis and Their Significance. Asia Pac. Allergy 5, 3-16. doi: 10.5415/ apallergy.2015.5.1.3

van Nunen, S. A. (2018). Tick-Induced Allergies: Mammalian Meat Allergy and Tick Anaphylaxis. Med. J. Aust. 208 (7), 316-321. doi: 10.5694/mja17.00591

Vechtova, P., Sterbova, J., Sterba, J., Vancova, M., Rego, R., Selinger, M., et al. (2018). A Bite So Sweet: The Glycobiology Interface of Tick-Host-Pathogen Interactions. Parasites Vectors 11 (1), 594. doi: 10.1186/s13071-018-3062-7

Versluis, A., Van Os-Medendorp, H., Kruizinga, A. G., Marty Blom, W., Houben, G. F., and Knulst, A. C. (2016). Cofactors in Allergic Reactions to Food: Physical Exercise and Alcohol are the Most Important. Immun. Inflammation Dis. 4 (4), 392-400. doi: 10.1002/iid3.120

Villalta, D., Pantarotto, L., Da Re, M., Conte, M., Sjolander, S., Borres, M. P., et al. (2016). High Prevalence of Sige to Galactose- $\alpha-1,3-$ Galactose in Rural Pre-Alps Area: A Cross-Sectional Study. Clin. Exp. Allergy 46 (2), 377-380. doi: 10.1111/ cea. 12655
Waserman, S., Bégin, P., and Watson, W. (2018). IgE-Mediated Food Allergy. Allergy Asthma Clin. Immunol. 14 (2), 15. doi: 10.1186/s13223-018-0284-3

Weiss, G. A., and Hennet, T. (2017). Mechanisms and Consequences of Intestinal Dysbiosis. Cell. Mol. Life Sci. 74 (16), 2959-2977. doi: 10.1007/s00018-0172509-x

Welsh, R. M., O’Donnell, C. L., Reed, D. J., and Rother, R. P. (1998). Evaluation of the Gal $\alpha 1-3 \mathrm{Gal}$ Epitope as a Host Modification Factor Eliciting Natural Humoral Immunity to Enveloped Viruses. . J. Virol. 72 (6), 4650-4656. doi: 10.1128/JVI.72.6.4650-4656.1998

Wickner, P., and Commins, S. P. (2014). The First 4 Central American Cases of Delayed Meat Allergy With Galactose-Alpha-1,3-Galactose Positivity Clustered Among Field Biologists in Panama. J. Allergy Clin. Immunol. 133, AB212. doi: 10.1016/j.jaci.2013.12.760

Wikel, S. K. (2018). Tick-Host-Pathogen Systems Immunobiology: An Interactive Trio. . Front. Biosci. 23, 265-283. doi: 10.2741/4590

Williams, T. J. (1979). Prostaglandin E2, Prostaglandin I2 and the Vascular Changes of Inflammation. Br. J. Pharmacol. 65 (3), 517-524. doi: 10.1111/ j.1476-5381.1979.tb07860.x

Wilson, J. M., McNamara, C. A., and Platts-Mills, T. (2019). IgE, $\alpha$-Gal and Atherosclerosis. Aging 11 (7), 1900-1902. doi: 10.18632/aging.101894

Wilson, J. M., Nguyen, A. T., Schuyler, A. J., Commins, S. P., Taylor, A. M., PlattsMills, T. A. E., et al. (2018). IgE to the Mammalian Oligosaccharide Galactose$\alpha-1,3-$ Galactose Is Associated With Increased Atheroma Volume and Plaques With Unstable Characteristics - Brief Report. Arterioscler. Thromb. Vasc. Biol. 38 (7), 1665-1669. doi: 10.1161/ATVBAHA.118.311222

Wilson, J., and Platts-Mills, T. (2019). Red Meat Allergy in Children and Adults. Curr. Opin. Allergy Clin. Immunol. 19(3):229-235. doi: 10.1097/ ACI.0000000000000523

Wilson, J. M., Schuyler, A. J., Schroeder, N., and Platts-Mills, T. A. (2017). Galactose- $\alpha-1,3-$ Galactose: Atypical Food Allergen or Model IgE Hypersensitivity? Curr. Allergy Asthma Rep. 17(1):8. doi: 10.1007/s11882017-0672-7

Wilson, J. M., Keshavarz, B, Retterer, M., Workman, L. J., Schuyler, A. J., McGowan, E. C., et al. (2021). A Dynamic Relationship Between Two Regional Causes Of Ige-Mediated Anaphylaxis: A-Gal Syndrome And Imported Fire Ant? The Journal of allergy and clinical immunology 147 (2):643-652.e7. doi: 10.1016/j.jaci.2020.05.034

Wölbing, F., Fischer, J., Köberle, M., Kaesler, S., and Biedermann, T. (2013). About the Role and Underlying Mechanisms of Cofactors in Anaphylaxis. Allergy 68 (9), 1085-1092. doi: 10.1111/all.12193

Wypych, T. P., and Marsland, B. J. (2018). Antibiotics as Instigators of Microbial Dysbiosis: Implications for Asthma and Allergy. Trends Immunol. 39 (9), $697-$ 711. doi: $10.1016 /$ j.it.2018.02.008

Yilmaz, B., Portugal, S., Tran, T. M., Gozzelino, R., Ramos, S., Gomes, J., et al. (2014). Gut Microbiota Elicits a Protective Immune Response Against Malaria Transmission. Cell 159 (6), 1277-1289. doi: 10.1016/j.cell.2014.10.053

Yu, W., Freeland, D., and Nadeau, K. C. (2016). Food Allergy: Immune Mechanisms, Diagnosis, and Immunotherapy. Nat. Rev. Immunol. 16 (12), 751-765. doi: 10.1038/nri.2016.11

Conflict of Interest: The authors declare that the research was conducted in the absence of any commercial or financial relationships that could be construed as a potential conflict of interest.

Copyright (C) 2021 Sharma and Karim. This is an open-access article distributed under the terms of the Creative Commons Attribution License (CC BY). The use, distribution or reproduction in other forums is permitted, provided the original author(s) and the copyright owner(s) are credited and that the original publication in this journal is cited, in accordance with accepted academic practice. No use, distribution or reproduction is permitted which does not comply with these terms. 